\title{
THE ASSESSMENT OF ECONOMIC AND ECOLOGICAL POTENTIALS FOR THE IMPLEMENTATION OF RENEWABLE ENERGY SOURCES (RES) IN KRASNODAR REGION ADAPTATION OF A GERMAN PLANNING APPROACH USING GEOGRAPHIC INFORMATION SYSTEM (GIS)
}

\author{
A. Melnikova*, A. Pogorelov**, S. Jergentz*, O. Frör* \\ *University of Koblenz-landau.Landau, Germany,melnikova@uni-landau.de \\ **Kuban State University, Krasnodar, Russia,pogorelov_av@bk.ru
}

\begin{abstract}
Renewable energy is one of the key instruments in achieving international climate-protection targets and in developing sustainable energy strategies for a low-carbon and greenhouse gas (GHG) reduced power production. Having an enormous potential for the development of RES, Russia can essentially contribute to the climate change mitigation by including an effective use of renewables in its national energy policy and strategies.
\end{abstract}

Keywords: renewable energy potential, spatial analysis, Krasnodar region, energy scenario.

Introduction.Renewable energy can be defined as a power that comes from resources, which are naturally replenished, on a human timescale [2]. RES can replace conventional fuels in following fields: water and space heating, electricity generation, motor fuels and rural (off-grid) energy services. The aim of this study is the evaluation of wind, solar and biomass energy potentials of the Krasnodar region - southwestern region of Russia - through a comprehensive and interdisciplinary assessment of socio-economic, ecological and political features of the region.

Russian national energy strategy stimulates the expansion of RES, hence there is a unique opportunity window for taking an essential step towards a green energy supply for this region. This study project aims to develop and foster an innovative model for changing the energy and land use infrastructure. Since energy plays a special role in the economic relations between Germany and Russia, there is a large potential for cooperation and technology transfer in the sector of RES. Currently, the efforts of the European Union under the TACIS program and the TREE project (funded by the German Federal Ministry of Economics and Technology) are under way to assist Russian partners in implementing renewable energy technologies. Beyond that, the Russian-German Energy Agency RuDEA, headquartered in Moscow, promotes and supports since 2009 RES installation concepts.

Our bilateral scientific research is developing an integrated planning tool for renewable energy production and reduction of GHG emissions in agricultural and touristic areas. The tool allows assessing ecological (i.e. technical) potentials with an integration of economic considerations. Later, this tool can be adapted to other regions of Russia. The main results of the project will (1) produce appropriate information about available RES and GHGrelated land use changes in Krasnodar region; (2) provide correct analysis and data for the regional renewable energy programs; (3) develop an adequate level and quality of scientific support; (4) evaluate the environmental implications of all RES proposed; and (5) demonstrate necessary regulatory, technical and methodological documentation and software for designing, constructing and operating renewable energy generating facilities. The results of this paper can draw the attention of decision makers to initiate a sustainable development wind energyproduction in Russia [11].

Problem statement.The study region Krasnodar is a 76,000 sq. km large federal subject of southwestern Russia with a promising availability of RES (fig. 1), which is a still unused option to cover a substantial part of the regional energy demand. As tourism and agriculture are the most valuable economic sectors in Krasnodar, the expansion of RES will help maintaining high ecological standards and economic competitiveness. The transition to green energy supply is leading to (1) decentralization of energy grids from the central energy producers; (2) autonomy and sustainable development of rural areas; (3) supply of the agrarian and touristic sector with low-carbon energy.

However, Russia encounters some barriers for the successful development and use of RES. The International Finance Corporation (IFC) report Renewable Energy Policy in Russia: Waking the Green Giant has identified essential constraints in developing of RES (IFC 2011):

1. Lack of federal and regional renewable energy support programs;

2. Lack of necessary infrastructure for the successful development of electricity generation from RES;

3. Lack of necessary regulatory, technical and methodological documentation and software for design, construction and operation of renewable energy generating facilities;

4. Inadequate human resources;

5. Inadequate level and quality of scientific support;

6. Lack of appropriate information, including information about available RES and reliable data about the results of implemented projects.

From our perspective, the last two mentioned points are the most essential limitations, which are holding back a timely implementation of an energy infrastructure based on RES. 


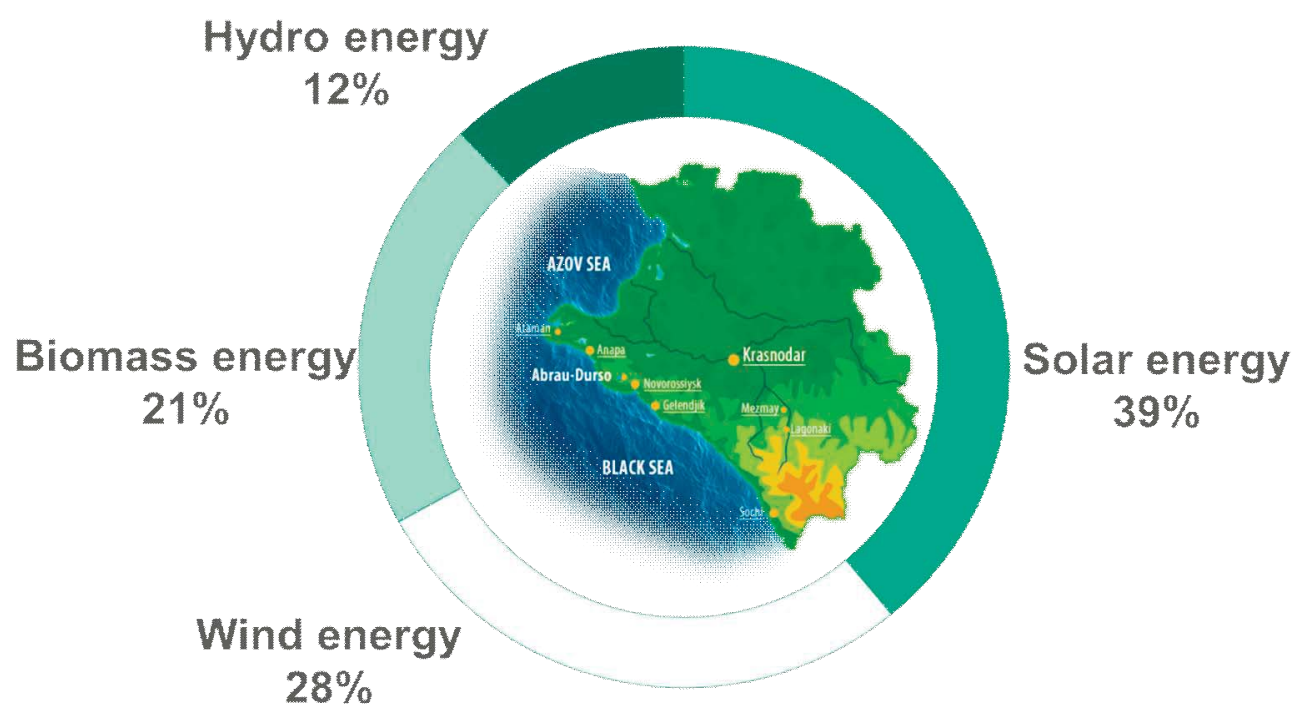

Fig. 1. Relative availability of RES in Krasnodar region. russiansc.com/south_of_russia_region/Krasnodar

Our scientific research is dealing with the development of an integrated planning tool for renewable energy production and reduction of GHG emissions in agricultural areas. Solar, wind, biofuel, geothermal energy and hydropower are available options to create a local/regional renewable energy industry and cover a substantial part of the regional energy demand. However, instead of exploring RES, this region meets almost all of the energy needs from conventional energy sources, $66 \%$ of which are imported from neighboring regions. This excessive reliance on conventional energy implies several disadvantages:

1. frequent interferences in the energy supply;

2. dependency from major energy production centers;

3. high prices for electricity/heating;

4. environmental pollution associated with GHG emissions.

The centralized power system in Krasnodar region needs changes by a number of renewable energy projects, which providing better electricity grid. Moreover, increasing decentralization in the delivery of electricity and heating leads to lower dependence of the remote settlements to the central network. This is not only contributes to the development of a positive image of the region, but also create new jobs and areas for sustainable economic development. Transition to RES is necessary ecological goal, but also brings well-distributed power production and storage capabilities. On the one hand, the transition to a smart grid, on the basis with the RES has to be evolutionary to keep the lights on; on the other hand, the issues surrounding such innovations are significant enough to demand major changes in power systems operating philosophy [6].

Materials and Methods.Under the framework of the EU-INTERREG Project Plan-RE, a GIS-based approach for the assessment of the local RES potentials via geo-data has been developed and successfully implemented. We aim to build upon this approach in a form adapted to the inhomogeneity of geo-data, the lack of appropriate energy infrastructure and management in Russia to assess socio-economic and ecological potentials for the implementation of RES in Krasnodar region. For this purpose, the REE-Mix assessment tool, which was developed for

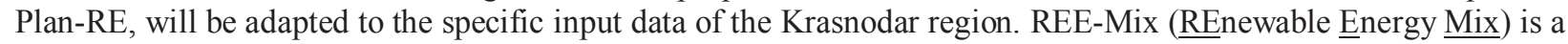
GIS-based tool for the calculation of potentials for the use RES on a local scale [7]. Due to the modular setup, REEMix is easily applicable to a variety of different regions. Elsaesser and Jergentz have developed the modular REEMix approach at the University of Koblenz-Landau, Campus Landau. The REE-Mix assessment methodology consists of the following modules:

1. Inventory: calculates the $\mathrm{CO}_{2}$ emission of the energy supply (electricity and heating) of the sectors housing, industries, commerce and transportation. It represents the current indicators of energy consumption and of GHG emissions per capita;

2. Yield Assessment: calculates the potentials for the relevant RES on a local scale in GIS. This potential will illustrate the technical potential as a maximum of energy that can be obtained from the region (= estimated yield of energy);

3. Feasibility Assessment: The technical potential is reduced by socio-economic factors, which are in conflict with the local use of RES. The module integrates the socio-economic aspects in the REE-Mix approach. For example, the number of stakeholders will correlate with the size of the suitable roof surface for photovoltaic. Beyond that, municipal legislation issues such as the listed buildings, conservation areas and planning law are integrated as single GIS layers.

4. Assessment of the Infrastructure: The inclusion of RES into traditional energy grid requires new concepts in managing the energy supply such as virtual power plants. Future energy systems will be demand-driven 
which changes the role of the local energy supplier. The modernization of the infrastructure will play a key role in the prospective energy storage and mobility in peripheral Russian settlements;

5. Efficiency/Sufficiency: The potentials of energy efficiency and energy savings are assessed. Especially housing and transportation sectors can be measured using GIS. The energy demand of buildings is simulated via 3D modeling setting up scenarios of redeveloping buildings. The module helps to identify locations for cogeneration plants and to implement local heat networks;

6. Optimization: The previous estimations are joined in the optimization module to simulate energy scenarios for the studied region. It is possible that various scenarios are created by the model, which needs to be discussed and agreed by local stakeholders. REE-Mix should reveal the opportunities for renewable energy supply and energy efficiency potentials for the modeled regions.

The main results of the REE-Mix assessment for the Krasnodar region are represented in GIS-maps with local potentials for wind, solar and biomass energy. Spatial analysis via GIS software (QGIS, SAGA GIS) is applied. These GIS-maps as well as other empirical (e.g. energy consumption) and analytical data (e.g. cost-benefit analysis for the implementation of RES) combined to develop the most efficient and economical reasonable energy production scenarios from the use of different RES. Technical assessment was calculated with a WindPower software. Relevant socio-economic aspects such as acceptance, adoption probabilities, economic viability of infrastructure investments and environmental implications of RES are included from the official data sources as http://www.gks.ru and kubanenergo.ru.

As described, the REE-Mix methodology integrates multiple assessment levels to estimate the implementation potential of RES in Krasnodar region. The expansion of RES holds an enormous potential for stimulating socioeconomic development of peripheral Russian territories. Due to the absence of other renewable energy projects for comparative assessment, the method approach has to be adapted to the local Russian conditions (Fig. 2).

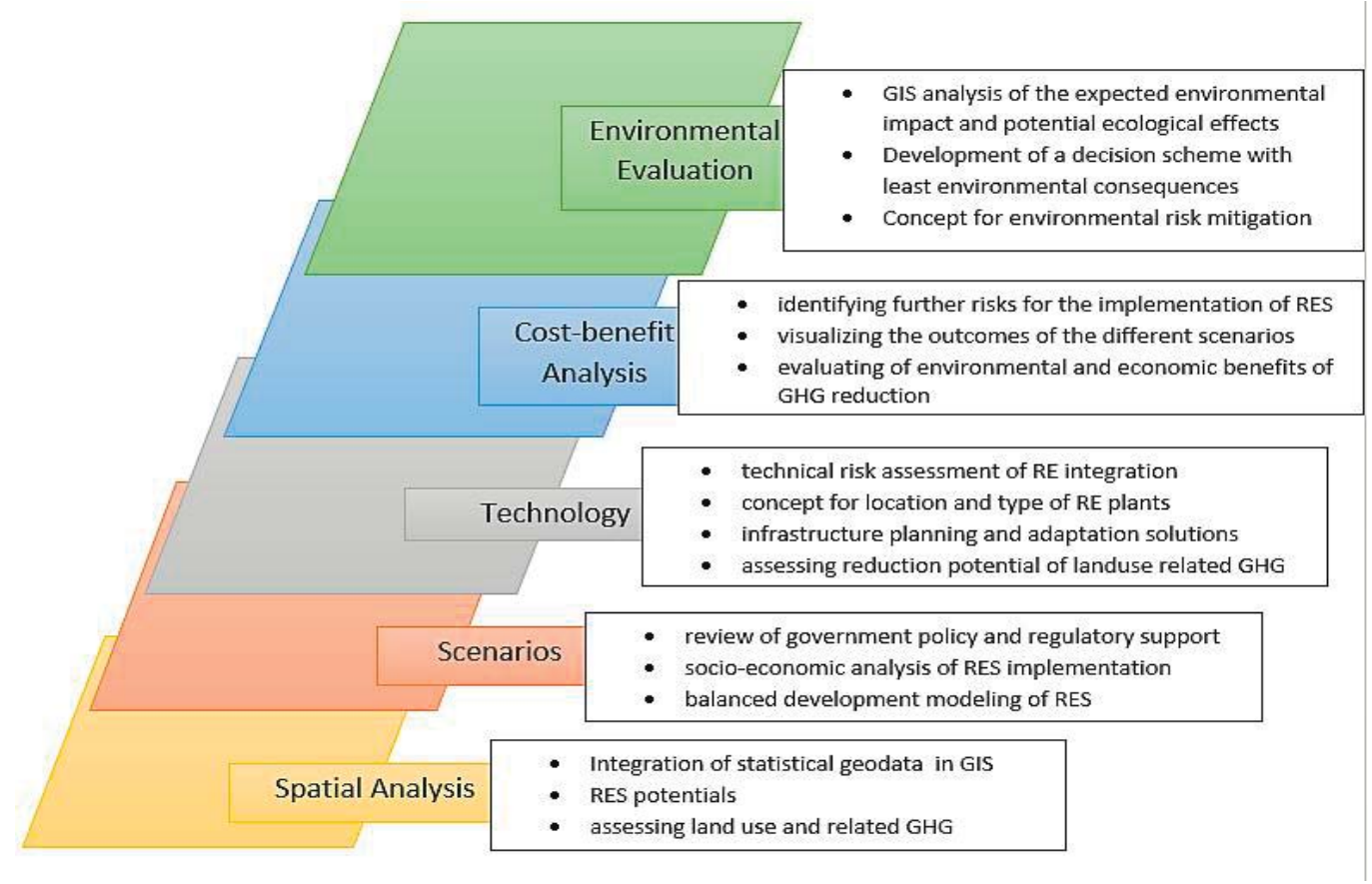

Fig. 2. Adapted work packages for the assessment of renewable energy potential in Krasnodar region

To our knowledge, there are no other studies with a comparably comprehensive and interdisciplinary RES potential assessment. With each assessment stage, the initial natural potential is assumed to decrease noticeably, but to an economically realistic output (tab.1).

Table 1

Renewable energy potential (mio tce/year) in Krasnodar region, (IEA International Energy Agency, 2003)

\begin{tabular}{|l|c|c|c|}
\hline Renewable energy & Economical potential & Technical potential & Environmental potential \\
\hline Hydropower & 65.2 & 124.6 & 360.4 \\
\hline Biomass energy & 35 & 53 & 10000 \\
\hline Wind energy & 10 & 2000 & 26000 \\
\hline Solar energy & 12.5 & 2300 & 2300000 \\
\hline Total & 122.7 & 4477.6 & 2336360.4 \\
\hline
\end{tabular}


Results and discussion. Comparative on-shore renewable energy potential for the Krasnodar region is demonstrated in Figure 3. Economically reasonable energy scenarios can be produced only with an appropriate environmental, technical and socio-economic data. Solar energy need longer economical calculations with the inclusion of the roof cadaster. These estimations are planned for the fall of 2015. In this paper, we focus on wind energy assessment and discussion of the first results, which include environmental, infrastructure (technical) yield and the first energy scenario for the Eyisk Wind park.

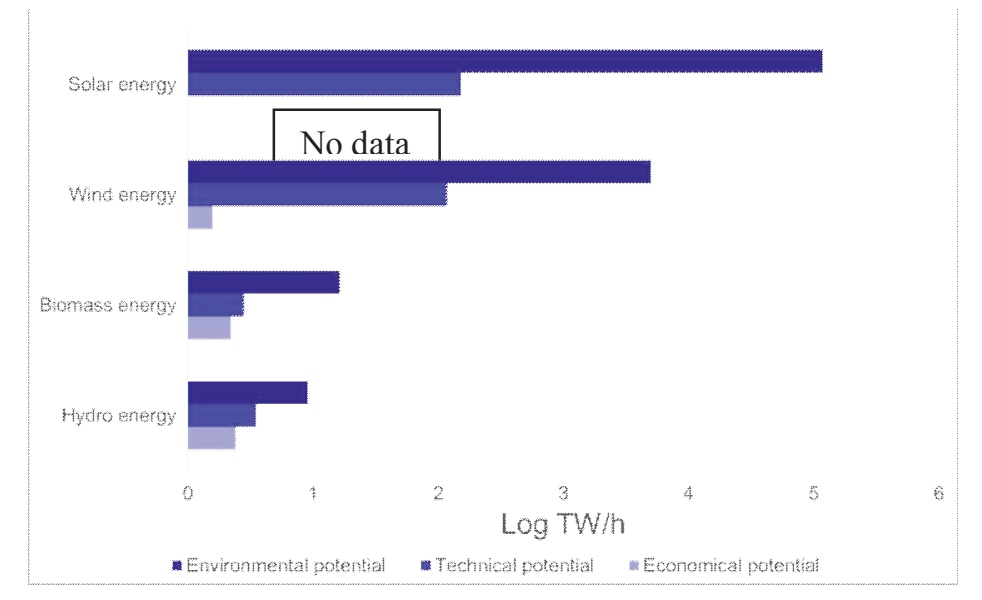

Fig. 3. Comparative renewable potential data in Krasnodar region

Production of the first wind power plants in Russia with market-oriented energy management started at the beginning of the 21 st century. However, the production of wind turbines takes place mainly in small private companies. Therefore, the Russian Federation is not a competitive producer capable to represent the country at the global market of alternative energy in general and wind turbines in particular. The extension of new wind energy capacity in Russia is slow -about $8 \%$ a year, which is one of the lowest in the world. In 2013, the government has launched a financial program supporting the development of renewable energy, according to which about $3.6 \mathrm{GW}$ of new wind power capacity will be provided by 2020 . It will be more than the half of the expected capacity of all power plants of renewable energy by 2020 (about $6 \mathrm{GW}$ ).

The government provided the target indicator - to increase the share of renewable energy to $4.5 \%$ of the total generated electricity by 2020. In our study we demonstrate that the sources of renewable energy in Krasnodar region, including wind sources are very unevenly distributed, making estimations of current energy potentials at local scale inevitable. In addition, the development of autonomous and decentralized power production from renewable sources will largely depend on the initiative of regional authorities and private companies.

From our assessment, the development of renewable power generation is not solely dependent on energy policy and regional authorities, but also on factors associated with climate and technical capabilities. From our calculations, the unrestricted wind energy potential (i.e. natural potential) in Krasnodar region would yield in total about 4,980 TW. General restrictions, such as protected areas and culture and recreational areas bring about a reduction of the natural potential to $105.3 \mathrm{TW}$, which is based on estimations for the technical onshore potential only. The socio-economic assessment with an analysis of cost and benefits, taxes, social acceptance (i.e. willingness to pay) and the life cycle assessment (LCA) is aimed to demonstrate factors, which will lead to a further reduction of the initial natural potential. Taking into account cost-benefit analysis we assume to reach $0.6 \mathrm{TW}$ by wind power potential. The result could be changed in next calculations, which will include socio-economical and detailed policy regulations assessment.

From today's perspective, promising locations for the construction of large wind parks in Krasnodar region are Anapa, Temryuksky district, Taman, Novorossiysk, Kerch strait and Yeisk district (Figure 4 and 5). The most efficient wind power plants could be considered in locations having wind speed above $7.2 \mathrm{~m} / \mathrm{s}$ at $80 \mathrm{~m}$ hub height. Further advantages of these locations are a well-developed electricity network structure with transmission electric lines of $220 \mathrm{~kW}$. An existing dense transport grid provides quick and inexpensive delivery of wind power installations to the consumers (i.e. districts, cities and villages).

In terms of economic feasibility, wind energy scenarios were calculated for locations with a minimum power capacity of $25 \mathrm{MW}$ (fig.6). However, the estimated average cost per unit of electricity must incorporate construction costs for turbines and transmission facilities, borrowed funds, returns to investors (including costs of risks), estimated annual production, and other components, averaged over the projected life cycle of the equipment, which may be in excess of twenty years. Estimations of energy costs are highly dependent on these assumptions, so published figures on costs can differ substantially (Helming, 2004). 


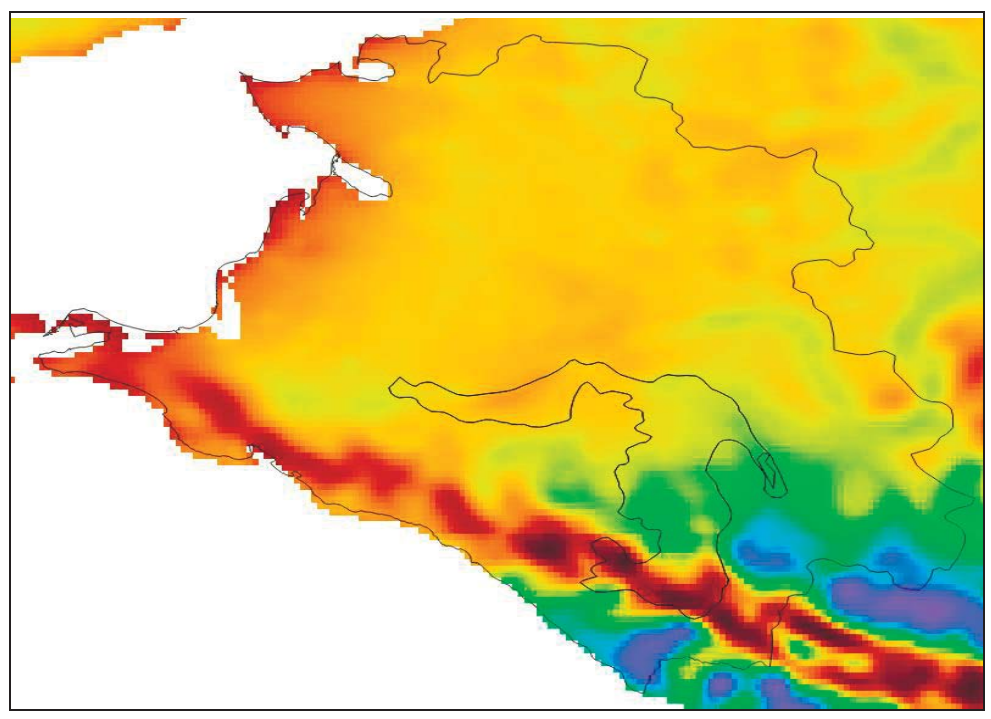

3 TIER's Global Wind Dataset 5 km onshore wind speed at $80 \mathrm{~m}$ height.

Legend:

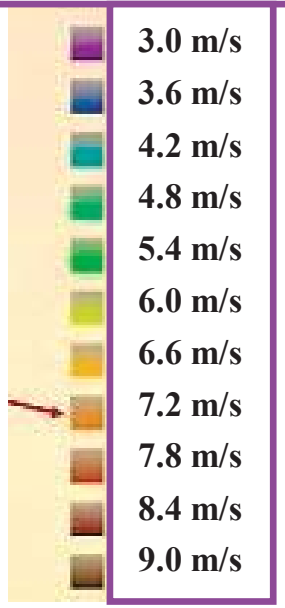

Fig. 4. Wind energy potential at 80 height from Global Atlas of International Renewable Energy Agency (IRENA)

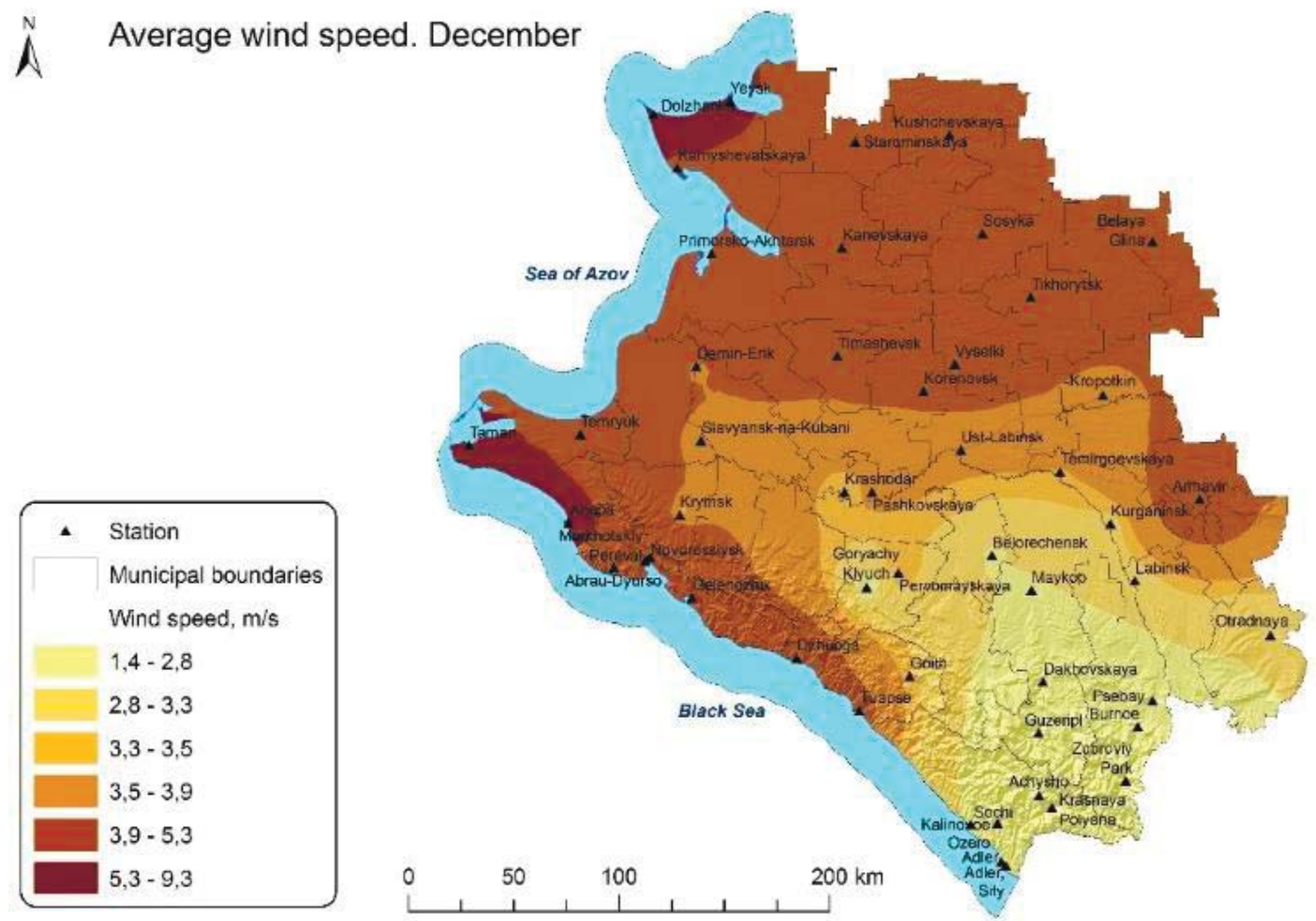

Fig.5. Average wind speed for December from 45 meteorological stations for a period of 20 years.

Calculated by the Kuban State University (KSU, Russia). Deep brown are the best suitable locations for wind power installations

The reliable supply of electric power is a critical element of the regional economy. The new operating strategies for environmental compliance, when combined with the aging transmissions and distribution infrastructure, challenge the security, reliability, and quality of the electric power supply [6]. During the preparations for the Winter Olympics in Sochi, a modern one replaced a large part of old energy infrastructure in Sochi district. Unfortunately, this modernization did not touch all the districts of the Krasnodar Territory, but it formed the basis for the continuation of the network update.

Krasnodar region is systematically suffering from the frequent blackouts and interferences in the departmentsYeiskii, Krymskii, Abinskii, Temryikskii, Krasnoarmeiskii, Novorossiisk, Gelendzhik, Central (Krasnodar city), Tyapsinskii, Dinskoi, Otradnenskii, Mostovskoi, Labinskyi, Kerganinskyi and Goryache-Kluchevskoi (fig. 7). 


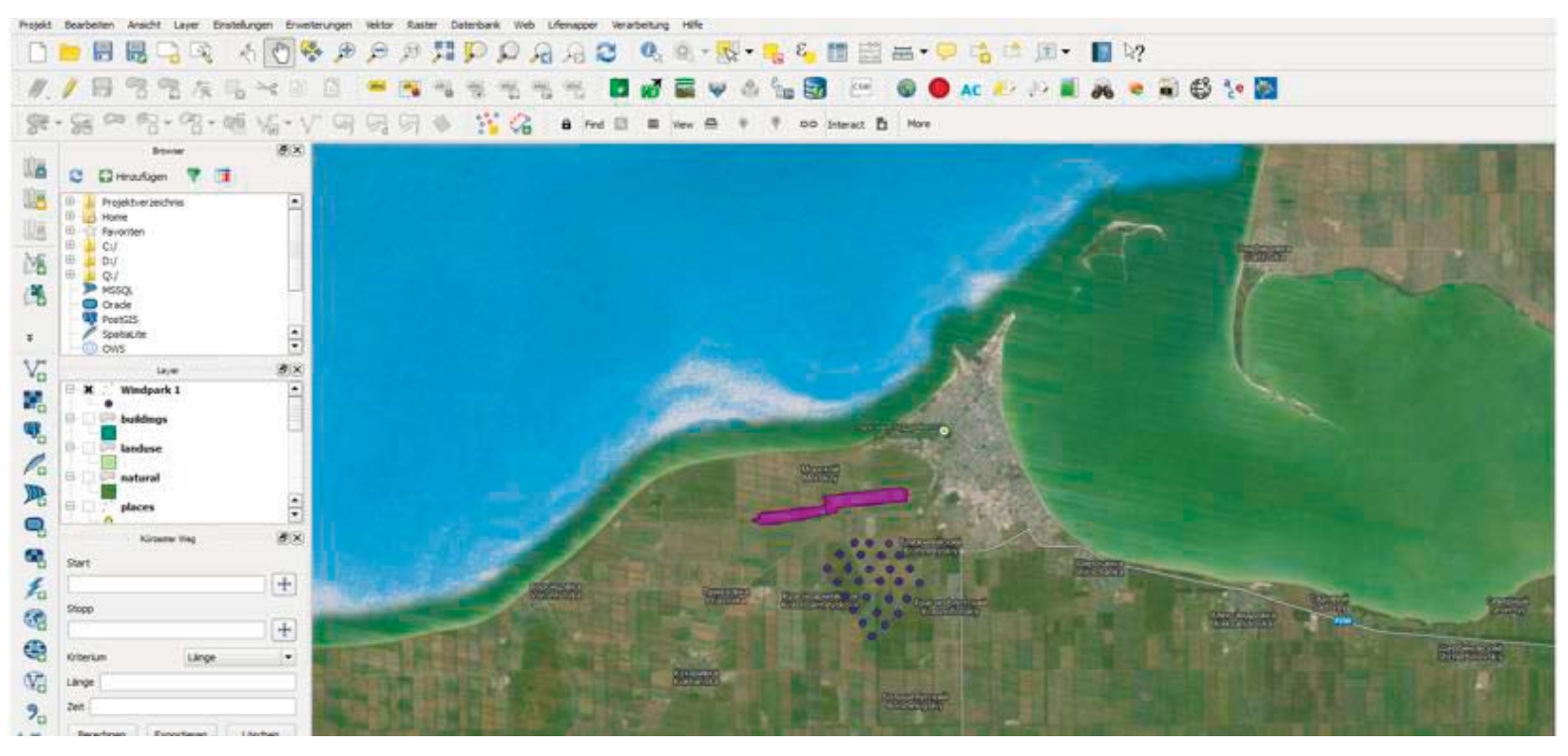

Fig. 6. Project of a wind park for 25MWh power near the city Yeisk (North-West coastal side of Krasnodar region). Points are windmills, the polygon in the northern direction is an airport (marked as a constraint).

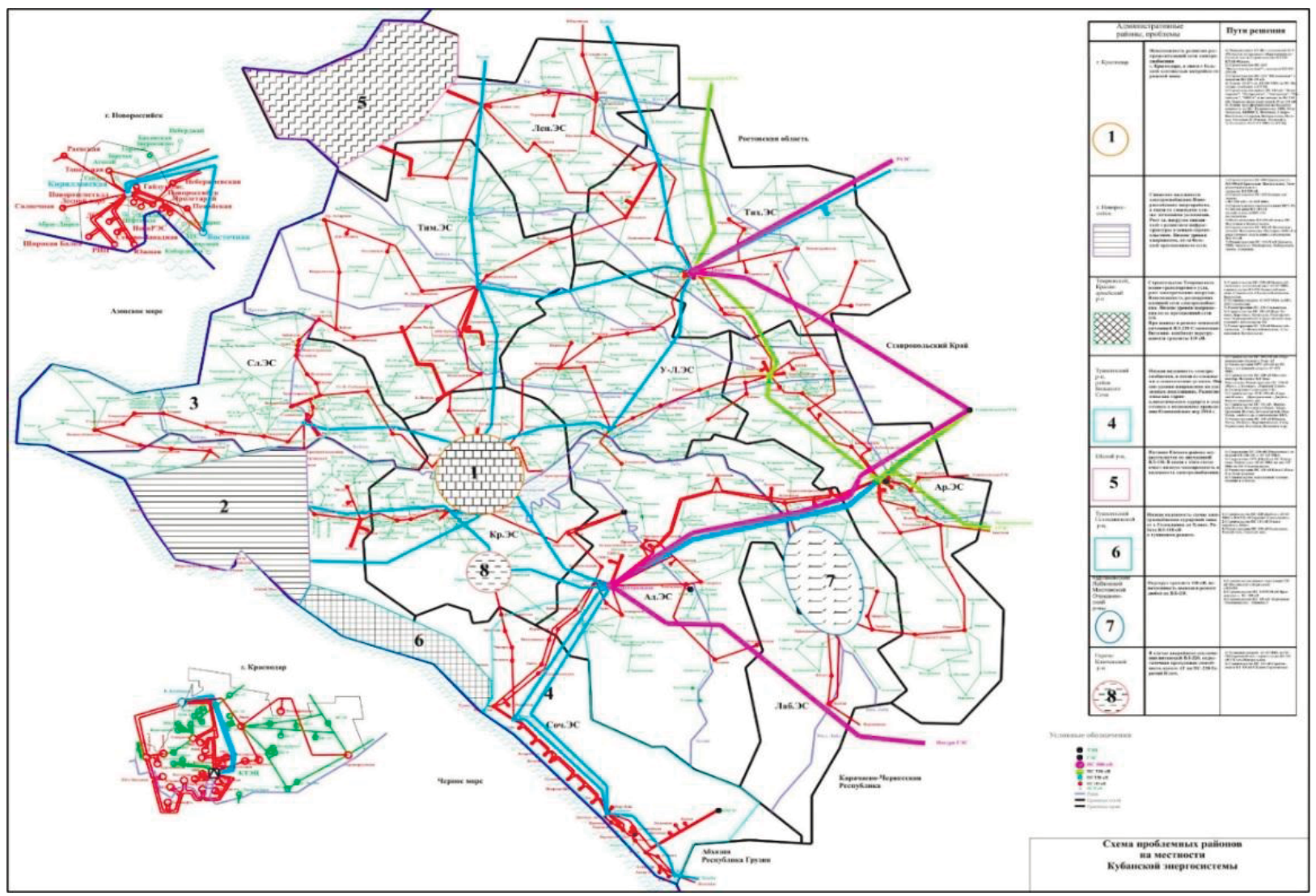

Fig. 7. Energy infrastructure and blackouts areas of the Krasnodar region from KubanEnergo

Our methodology takes into account a large number of factors for the successful implementation of RES. Nevertheless, it is important to include regional peculiarities and specific problems of Krasnodar region and adapt them to the planning approach. As infrastructure planning plays a key role in power delivery, we found in an assessment on data from KubanEnergo typical causes of accidents in energy providing systems:

1. Inability to setup power distribution networks in residential areas with a dense building density

2. Breakdowns of the energy infrastructure due to hazardous natural events;

3. Growth of electrical loads in main touristic season;

4. Low-level resistance because of the long-haul network;

5. Inability to expand the external power supply network; 
6. Low voltage levels at remote substations;

7. Electrical distribution scheme has low maneuverability and reliability.

Conclusions. The described adaptation of the methodology for the assessment of the socio-economic and ecological potentials for the implementation of RES can be used as a standard assessment tool for Krasnodar region and other regions of Russia. Decentralized renewable power generation is able to stimulate investments and economic growth in the periphery and provide sustainable conditions for a competitive economic development of the Russian green energy sector [10]. Peripheral settlements will gain more independence and control over their energy supply and will have the opportunity to act as energy suppliers at the electricity market by selling their surplus of the renewable energy production.

Our research project is cooperating with the Kuban State University (KubSU, Russia), the Ministry of Energy and Industry, the Ministry of Natural Resources and the Ministry of Agriculture and Processing Industry of Krasnodar region. It is planned to implement the results of the study in the regional energy program "Energy and energy efficiency of the Krasnodar region for the period 2011-2020". The Ministry of Energy can use the results for the capacity development of the energy infrastructure in Krasnodar region. Beyond that, our assessment can be applied as decision support for strategies dealing with the implementation of RES. The adaptation of regulatory measures and measures of climate protection will establish new regional energy standards. Public services will be created based on open source information and metadata.

The project aims to support bilateral technical and methodological transfer between the University of Koblenz-Landau (UKL) and KubSU. The cooperation between UKL and KubSU will close important knowledge gaps in renewable energy sector of Russia. For Germany, it is an opportunity to test new techniques of analysis and their adaptation in emerging countries. Thus, renewable energy assessment and development is a promising field for the cooperation between Germany and Russia.

Acknowledgments: the author would like to thank Prof. Dr. Anatolii Pogorelov at the Kuban State University, Prof. Dr. Oliver Frör, Dr. Stefan Jergentz Dipl.-Vw. Ado Ampofo, Dipl.-Umw. Nikita Bakanov at the University of Koblenz-Landau, KubanEnergo IRENA, free software QGIS and SAGA GIS, DAAD and Stipendienstiftung Rheinland-Pfalz.

\section{REFERENCES}

1. Chernitsa S. and Churikov A. (2010): Prospects for the Development of Renewable Energy in Russia: Sector Overview, Electrical Market. No. 1-2 (31-32).

2. Ellabban O. and Abu-Rub H. (2014) Renewable energy resources: current status, future prospects and their enabling technology. Renewable and Sustainable Energy Reviews 39, 748-764, p. 749.

3. Huld T., Dunlop E., Beyer H. G., Gottschalg R. 2013 Data sets for energy rating of photovoltaic modules. Solar Energy, p. 267-279

4. IEA International Energy Agency, (2003). World Energy Investment Outlook 2003. Retrieved from http://www.worldenergyoutlook.org/media/weowebsite/2008-1994/weo2003.pdf

5. IFC International financial corporation, (2011): Renewable Energy Policy in Russia: Waking the Green Giant. IFC Report. URL: http://www.ifc.org/ ifcext/eca.nsf/ Content/RussiaProjectRE

6. Ipakchi A., \& Albuyeh F. (2009). Grid of the future. IEEE Power and Energy Magazine, 7(2), 52-62. doi:10.1109/MPE.2008.931384

7. Jergentz S. and Elsaesser D. (2013) presentation: The REE-Mix Spatial Decision Support System: Assessing the Potentials for Regional Renewables.

8. Jordan G. (eds.) Digital Terrain Modelling, Development and Applications in a Policy Support Environment, Series: Lecture Notes in Geoinformation and Cartography, Springer, pp. 67-82, ISBN 3-540-36730-6.

9. Lukutin B.V., O.A. Syrzhikova O.A., Shandarova E.B. (2008): Renewable energy in decentralized electricity supply: monography. Moscow, Elektroatomizdat, 2008. pp. 22-51.

10. Øverland I. and Kjoernet H. (2010): Russian Renewable Energy - The Potential for International Cooperation. Energy \& Natural Resources Law. pp. 560-564.

11. Siyal S. H., Mörtberg U., Mentis D., Welsch M., Babelon I., \& Howells M. (2015). Wind energy assessment considering geographic and environmental restrictions in Sweden: A GIS-based approach. Energy, 83, 447-461. doi:10.1016/j.energy.2015.02.044. 